\title{
Ecological Risk of Nonylphenol in China Surface Waters Based on Reproductive Fitness
}

Xiaowei Jin, ${ }^{\dagger \dagger}$ Yeyao Wang, ${ }^{\dagger}$ Wei Jin, ${ }^{\S}$ Kaifeng Rao, ${ }^{\ddagger}$ John P. Giesy, ${ }^{\|, \perp, \#, \boldsymbol{\Lambda}}$ Henner Hollert, $^{\bigcirc}$ Kristine L. Richardson, $\triangle$ and Zijian Wang*,+⿳亠丷厂

${ }^{\dagger}$ Department of Analytical Technique, China National Environmental Monitoring Center, Beijing 100012, China

${ }^{\ddagger}$ State Key Laboratory of Environmental Aquatic Chemistry, Research Center for Eco-Environmental Sciences, Chinese Academy of Sciences, Shuangqing Road 18, Haidian District, Beijing 100085, China

${ }^{\S}$ Shijiazhuang Environmental Monitoring Center, Shijiazhuang, Hebei 050021, China

"Department of Veterinary Biomedical Sciences and Toxicology Centre, University of Saskatchewan, Saskatoon, Saskatchewan S7N 5A1, Canada

${ }^{\perp}$ State Key Laboratory of Pollution Control and Resources Reuse, School of the Environment, Nanjing University, Nanjing, Jiangsu 210046, PR China

\# Department of Zoology, and Center for Integrative Toxicology, Michigan State University, East Lansing, Michigan 48824, United States

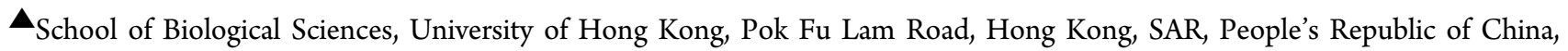

OInstitute for Environmental Research, RWTH Aachen University, Aachen, North Rhine-Westphalia 52074, Germany

$\triangle$ Environmental Toxicology Program, Department of Environmental Sciences, University of California, Riverside, California 92521, United States

\section{Supporting Information}

ABSTRACT: It has been recognized that ecological risk assessment based on traditional endpoints of toxicity are unable to provide adequate protection because some chemicals may affect reproductive fitness of aquatic organisms at much lower concentrations. In this paper, predicted no effect concentrations (PNECs) for 4-nonylphenol (NP) were derived based either on endpoints of survival, development, and growth or on some nonlethal biomarkers of reproduction, biochemical and molecular biology data. The PNECs derived from reproductive lesion ranged from 0.12 to $0.60 \mu \mathrm{g} \mathrm{NP} \mathrm{L}^{-1}$, which was significantly lower than those derived from other endpoints. An assessment of ecological risks posed by NP to aquatic organisms in surface waters of China was conducted based on concentration levels of NP in 16 surface waters of 4 major river basins and PNECs derived from reproductive fitness by a tiered ecological risk assessment (ERA). The results showed that $14.2 \%$ and $76.5 \%$ of

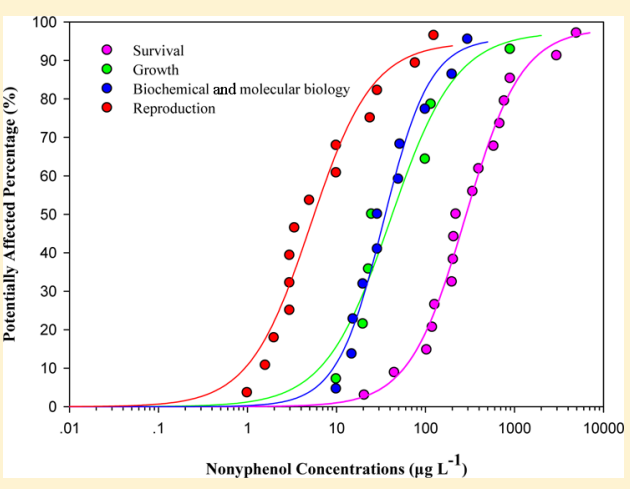
surface waters in China may have ecological risks resulting from reproductive fitness if the thresholds of protection for aquatic organisms were set up as 5\% ( $\mathrm{HC5}$ ) and 1\% ( $\mathrm{HC1}$ ), respectively. The risks were significantly greatest in the Yangtze River Basin than in other major river basins. In comparison with the risks assessed based on traditional endpoints, such as lethality, for those chemicals causing adverse effects on reproduction due to modulation of endocrine function, to be protective of ecosystem structure and function, lesser PNECs, based on sublethal effects of reproduction, were appropriate.

\section{INTRODUCTION}

There have been increasing detections of hormones, hormone mimics, and other endocrine-disrupting substances in water, some of which have been found to affect reproductive fitness of aquatic organisms. Prominent among these endocrine disrupting chemicals (EDCs) are the alkylphenols and, in particular, 4nonylphenol (NP), which is widely a degradation product of nonionic surfactants, such as nonylphenol ethoxylates (NPEs), that are found in detergents, emulsifiers, pesticides, lubricants, and oil additives, all of which are commonly used in daily life. ${ }^{1}$ NP has been found worldwide in wastewater discharges, sewage-treatment plant effluents, natural water, and sediments. ${ }^{1-3}$ Field surveys have revealed that NP occurs at mg $\mathrm{L}^{-1}$ concentrations in aquatic environments ${ }^{4,5}$ and has been detected in watersheds and drainage areas of China at relatively great concentrations. ${ }^{6-8}$ Because NP and NPEs are ubiquitous, persistent, easily bioaccumulated, and have the potential to

Received: August 25, 2013

Revised: December 15, 2013

Accepted: December 16, 2013

Published: December 16, 2013 
cause toxic effects of aquatic organisms, these chemicals have attracted attention in the past few years. Nonylphenol has been referred to in the list of priority substances in the Water Frame Directive and in the third draft Working Document on Sludge of the EU. ${ }^{5}$ Previous investigations have shown that NP was estrogenic both in vivo and in vitro. ${ }^{9-12} \mathrm{NP}$ can affect reproduction of teleost fishes. Notably, NP induces production of the female-specific, egg-yolk precursor vitellogenin (VTG) in livers of males, is associated with testis-ova, and decreases fecundity and fertility. ${ }^{12-16}$ Due to the potential for toxicity of $\mathrm{NP}$ to aquatic organisms, analyzing the ecological risk of NP is crucial to protection of aquatic organisms and the surface waters of China.

An important step in ecological risk assessment of chemicals is determination of the maximum concentration at which the ecosystem is protected, i.e., the predicted no-effect concentration (PNEC). PNECs are usually derived based on a laboratory toxicity test (especially for chronic) using welldefined protocols on a limited number of species. ${ }^{17}$ Despite the numerous toxicity data of NP available on fish, Daphnia and algae, no final decision was made regarding PNEC derivation for NP since its specific mode of action to aquatic organisms is still unclear. International organizations such as the USEPA and $\mathrm{EU}$ as well as other governmental agencies have issued various assessment reports on the risk management of NP. However many of them were mainly focused on the toxicity of NP to aquatic organisms and derived a toxicity threshold with assessment factor. ${ }^{18-20}$ USEPA have derived a criterion continuous concentration (CCC) of $6.59 \mu \mathrm{g} \mathrm{L}^{-1}$ for protection of aquatic life using acute to chronic ratios (ACRs) (also called application factors, AFs). ${ }^{21}$ However, it has been demonstrated that NP affects the reproductive system of aquatic organisms at a concentration of $1 \mu \mathrm{g} \mathrm{L}^{-1}$ more or less. ${ }^{22}$ Use of ACRs has been criticized. ${ }^{23-26}$ In some cases, average ACRs might be inadequate to extrapolate accurately from acute to chronic value. $^{27,28}$ In the EU risk assessment report on nonylphenol of 2001 a no observable effects concentration (NOEC) of 0.33 $\mu \mathrm{g} / \mathrm{L}$ was derived, based on the endocrine disruptive potential of NP on fresh water fish. ${ }^{29}$ Lin et al. suggested that PNEC values of 4-NP ranging between 0.82 and $2.10 \mu \mathrm{g} / \mathrm{L}$ affect medaka population growth. ${ }^{30}$ However, the evaluation data was mainly concentrated on toxicity of single fish species and lacks consideration to other aquatic organisms.

Survival, development, and growth are traditional measurement endpoints in ecotoxicology. Because these effects can be readily linked to population-concentration effects, they are favored for derivation of PNECs that protect aquatic organisms. Some researchers have indicated that traditional methods for assessment of effects with standard assessment endpoints of toxicity are unable to provide adequate protection of aquatic organisms because some contaminants have been found to affect reproductive fitness at concentrations less than those based on survival and growth. ${ }^{31}$ Nevertheless, nonlethal biomarkers such as vitellogenin (VTG), secondary sexual characteristics, gonadso-matic index (GSI), concentrations of steroids in blood plasma, and gonadal histology are considered "measurement endpoints" in assessment of risks of endocrinedisrupting chemicals (EDs) to aquatic organisms. ${ }^{32}$

In the present study, predicted no effect concentrations (PNECs) of NP were derived, based either on endpoints of survival, development, and growth or on some nonlethal biomarkers of reproduction, biochemical, and molecular biology data. In addition, an assessment of the risks posed by
$\mathrm{NP}$ to aquatic organisms in surface waters of China was conducted by comparing PNECs derived based on reproductive fitness to concentrations of NP by applying a probabilistic ecological risk assessment (PERAs), which qualified and quantified ecological risks through exposure and effect probability distributions. Probabilistic assessments are considered to be an improvement on the hazard quotient (HQ) approach and, thus, recommended for high tiers in the ecological risk assessment (ERA) process. ${ }^{33}$ Because PERAs can better describe the likelihood of exceeding the effect thresholds and the risk of adverse effects, ${ }^{34}$ this approach has been adopted by a number of researchers. ${ }^{35-39}$

\section{MATERIALS AND METHODS}

2.1. Data Collection and SSD Generation. Toxicity data for NP were collected from existing toxicity databases (e.g., ECOTOX Database, http://cfpub.epa.gov/ecotox/) and published in the literature and government documents following the principles of accuracy, relevance, and reliability. ${ }^{31,40}$ For acute toxicity data, selected measurement endpoints were the median lethal concentration $\left(\mathrm{LC}_{50}\right)$ or median effect concentration $\left(\mathrm{EC}_{50}\right)$ based on immobility for animals and biomass or growth for plants. For chronic toxicity data, NOECs were calculated from the available literature. When a NOEC was not available, MATC or LOEC or $\mathrm{EC}_{x}$ was used. In the case of multiple data on the same endpoint and species, the geometric mean was used.

Toxicity data for effects of NP on aquatic organisms were divided into four categories in accordance with different endpoints as follow: Mortality data consider the effect of lethality, livability, and behavioral inhibition to aquatic organisms. Growth data consider the effect of development and growth inhibition to aquatic organisms. Reproduction data consider the effect of fecundity, fertilization rate, hatchability, VTG, gonadosomatic index, gonadal histology, and multiple generation effect to aquatic organisms. Biochemical and molecular biology data consider the effect of induction or inhibition of enzyme activities, up-regulation of the expression of stress proteins, changes in RNA or DNA incidences of mutagenicity, or carcinogenicity. Toxicity data used for the Species Sensitivity Distributions (SSD) calculation are reported in the Supporting Information (Table S1).

SSDs were constructed by fitting cumulative probability distributions that plotted the concentration associated with eliciting a particular response from a particular species as a function of rank-assigned centile. ${ }^{41-43}$ Usually, a point estimate known as the $\mathrm{HC}_{5}$ (hazardous concentration for $5 \%$ of species) is calculated from the SSD. This concentration is predicted to exceed no more than $5 \%$ of species effect concentrations. In this study, a log-normal distribution model was fitted to different endpoint data points of NP, and the fit of the model was evaluated using the Kolmogorov-Smirnov test. $\mathrm{HC}_{5}$ values were then derived by use of the ETX 2.0, RIVM software packages, and final PNECs were derived by dividing the $\mathrm{HC}_{5}$ by an application factor of 5.0. ${ }^{44}$ The factor 5 was chosen based on the amount of supporting evidence, such as non-native species data, multispecies data present, and the presence of information based on field data. Sensitivity distributions were compared using the two-sample Kolmogorov-Smirnov test using the SPSS Version 17 software.

2.2. Exposure Concentration of NP. Samples from 16 surface waters, including reservoirs and rivers that supply water to local waterworks, were collected between March 2010 and 
July 2010 (Table 1). The study area covered four out of the seven main river systems of China. Samples were collected in

Table 1. Site Information and Exposure Concentration of Nonylphenol

\begin{tabular}{|c|c|c|c|}
\hline site & type & coordinate & $\operatorname{concn}^{b}\left(\mathrm{ng} \mathrm{L}^{-1}\right)$ \\
\hline \multicolumn{4}{|c|}{ Liao River ${ }^{a}$} \\
\hline $\mathrm{S} 1$ & reservoir & $124.101 \mathrm{E}, 41.886 \mathrm{~N}$ & $30.05 \pm 3.97$ \\
\hline $\mathrm{S} 2$ & reservoir & $125.404 \mathrm{E}, 41.292 \mathrm{~N}$ & $54.27 \pm 7.34$ \\
\hline \multicolumn{4}{|c|}{ Hai River ${ }^{a}$} \\
\hline S3 & reservoir & 116.840 E, $40.490 \mathrm{~N}$ & $109.22 \pm 12.37$ \\
\hline \multicolumn{4}{|c|}{ Yangtze River $^{a}$} \\
\hline S4 & river & 106.449 E, $29.597 \mathrm{~N}$ & $168.25 \pm 5.48$ \\
\hline S5 & river & 106.554 E, $29.570 \mathrm{~N}$ & $100.21 \pm 7.97$ \\
\hline S6 & river & 106.529 E, $29.508 \mathrm{~N}$ & $123.58 \pm 10.29$ \\
\hline S7 & river & 118.694 E, $31.994 \mathrm{~N}$ & $280.19 \pm 17.67$ \\
\hline S8 & river & 118.798 E, $32.142 \mathrm{~N}$ & $288.75 \pm 21.48$ \\
\hline S9 & river & 118.717 E, $32.049 \mathrm{~N}$ & $212.39 \pm 14.63$ \\
\hline S10 & lake & 120.223 E, $31.517 \mathrm{~N}$ & $232.73 \pm 14.65$ \\
\hline S11 & reservoir & 121.357 E, $31.492 \mathrm{~N}$ & $230.84 \pm 16.52$ \\
\hline $\mathrm{S} 12$ & river & $121.308 \mathrm{E}, 30.974 \mathrm{~N}$ & $259.63 \pm 14.21$ \\
\hline S13 & reservoir & $121.710 \mathrm{E}, 31.420 \mathrm{~N}$ & $224.13 \pm 18.57$ \\
\hline \multicolumn{4}{|c|}{ Pearl River ${ }^{a}$} \\
\hline S14 & reservoir & 114.603 E, $23.794 \mathrm{~N}$ & $58.33 \pm 4.23$ \\
\hline S15 & reservoir & 113.259 E, $23.807 \mathrm{~N}$ & $85.16 \pm 7.45$ \\
\hline S16 & reservoir & $114.149 \mathrm{E}, 22.571 \mathrm{~N}$ & $72.65 \pm 4.96$ \\
\hline
\end{tabular}

precleaned amber glass bottles. Prior to sample collection, the bottles were washed three times with water samples. To minimize contamination of samples, throughout sample collection and processing, use of personal care items and pharmaceuticals were discouraged. Samples were stored at $4{ }^{\circ} \mathrm{C}$ prior to treatment and were treated and prepared within $48 \mathrm{~h}$.

Water samples were filtered through prebaked glass fiber filters to remove insoluble materials and extracted using the SPE method. Water samples for quantification of 4-NP were spiked with BPA-d16 following published procedures. ${ }^{8}$ Concentrations were determined by use of an Agilent 6890 gas chromatograph equipped with an Agilent MSD 5975 mass spectrometer (USA). System control and data acquisition were achieved by use of ChemStation Software (USA). ${ }^{8}$ All data generated from the analysis were subject to strict quality control procedures. Recoveries of spikes of NP averaged $87.7 \%$ and were within the acceptable criteria. Limit of detection (LOD) and limit of quantitation (LOQ) of the target compounds were based on the standard derivations (SD) of seven replicates of spiked water at the concentration of $5 \mathrm{ng} \mathrm{NP}$ $\mathrm{L}^{-1}$. LOD was defined as three times SD, and LOQ was defined as nine times SD. The LOD and LOQ for source water were 0.10 to $0.65 \mathrm{ng} \mathrm{NP} \mathrm{L}{ }^{-1}$ and 0.20 to $1.3 \mathrm{ng} \mathrm{NP} \mathrm{L}^{-1}$, respectively.
2.3. Ecological Risk Assessment of NP. The probabilistic ecological risk assessment (PERA) was performed by using the Probabilistic Risk Assessment Tool (PRAT). ${ }^{33,45}$ In PERA, estimation of risk is described as being proportional to the degree of overlap of the distributions, and one method of displaying risk is through the use of joint probability curves (JPCs), which describes the probability of a particular set of exposure conditions occurring relative to the number of taxa that would be affected. ${ }^{38,39,45}$ The $x$-axis of the JPC represents the intensity of effects, while the $y$-axis represents their probability. Each point on the curve represents both the probability that the chosen proportion of species will be affected, and the frequency with which that magnitude of effect would be exceeded. The closer the JPC is to the axes, the less the probability of adverse effects. ${ }^{45}$ In addition for comparison ecological risks posed by NP among basins, deterministic HQs were also calculated by dividing measured concentrations in the environment (MECs) with PNECs.

\section{RESULTS AND DISCUSSION}

3.1. Predicted No Effect Concentrations of NP. Toxicity data used for the Species Sensitivity Distributions (SSD) calculation are reported in the Supporting Information (Table S1). A total of 17 toxicity data based on lethality and behavioral effects for aquatic species were collected for NP, including 6 fishes and 11 invertebrates. Concentrations for mortality ranged from 20.7 to 5,000, with a median of $761.1 \mu \mathrm{g} \mathrm{NP} \mathrm{L}{ }^{-1}$. Seven chronic NOEC values, based on the effect on development and growth, with 2 data points for fishes, 4 for invertebrates, and 1 for hygrophytes, respectively. The range of magnitudes of effects on growth was from 10.0 to 901 , with a median of 170.7 $\mu \mathrm{g}$ NP L ${ }^{-1}$. Fourteen results based on reproduction including fecundity, rate of fertilization, hatchability, and effects on multiple generations, included 5 fishes, 8 invertebrates, and 1 planktonic alga. The NOECs (or $\mathrm{EC}_{x}$ ) ranged from 1.0 to 125 , with a median of $21.24 \mu \mathrm{g} \mathrm{NP} \mathrm{L}{ }^{-1}$. In addition, a total of 11 toxicity data were collected based on biochemical and molecular biology endpoints, with concentrations ranging from 10.0 to 300 , with a median of $74.6 \mu \mathrm{g} \mathrm{NP} \mathrm{L}{ }^{-1}$. Parameters of species sensitivity distributions for NP based on different endpoints are shown in Table 2.

Toxicity data for NP based on various endpoints were determined, based on results of the Kolmogorov-Smirnov test $(p<0.05)$ to meet the assumption normally for application of parametric statistics. The calculated $\mathrm{HC}_{5} \mathrm{~s}$ for each measurement endpoint ranged from 0.60 to $30.03 \mu \mathrm{g} \mathrm{L}^{-1}$ (Table 2). The final PNECs were calculated as the derived $\mathrm{HC}_{5}$ with a $50 \%$ uncertainty divided by a factor 5 . The PNEC derived from reproduction data was lesser than those derived based on growth or biochemical and molecular biology data, and the PNEC derived from survival data was the greatest.

Table 2. Parameters of Species Sensitivity Distributions for Nonylphenol Based on Different Endpoints ${ }^{a}$

\begin{tabular}{|c|c|c|c|c|c|c|}
\hline endpoint & $\mathrm{N}$ & mean & SD & $\mathrm{K}-\mathrm{S}$ test for normality & $\mathrm{HC}_{5}$ with $50 \% \mathrm{CI}\left(\mu \mathrm{g} \mathrm{L}^{-1}\right)$ & $\operatorname{PNEC}\left(\mu \mathrm{g} \mathrm{L}^{-1}\right)$ \\
\hline survival & 17 & 761.6 & 1295 & 0.5224 & $30.03(9.81-62.91)$ & 6.01 \\
\hline growth & 7 & 170.7 & 324.7 & 0.7711 & $3.77(0.29-13.02)$ & 0.75 \\
\hline biochemical and molecular biology & 11 & 74.6 & 93.1 & 0.6142 & $6.43(1.88-13.19)$ & 1.29 \\
\hline reproduction & 14 & 21.24 & 36.1 & 0.7701 & $0.60(0.15-1.43)$ & 0.12 \\
\hline
\end{tabular}

${ }^{a} \mathrm{~N}$ refers to number. SD refers to standard deviation. HC5 refers to hazardous concentration for $5 \%$ of species. PNEC refers to predicted no-effect concentration. 
The sensitivity distribution for NP based on various endpoints demonstrated that effects on reproduction occurred at lesser concentrations than those based on lethality, growth, or biochemical and molecular biology (Figure 1) and were

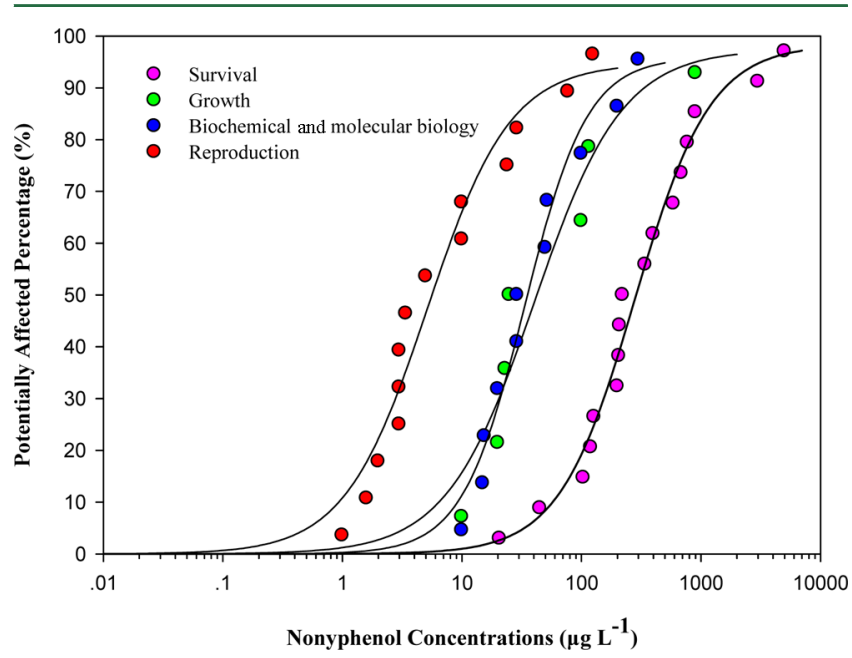

Figure 1. Species sensitivity distribution of nonylphenol based on different tested endpoints.

significantly different from data survival $\left(k s=2.186, \mathrm{n}_{1}=14\right.$, $\left.\mathrm{n}_{2}=17, p<0.001\right)$ and growth $\left(k s=1.409, \mathrm{n}_{1}=14, \mathrm{n}_{2}=7, p=\right.$ 0.039 ). PNECs based on reproductive fitness occurred at lesser concentrations than other test endpoints. Previous investigations have shown that NP was estrogenic and affects teleost reproduction. ${ }^{9-12}$ This conclusion is consistent with the results of the present assessment.

An important step in ecological risk assessment of chemicals is calculation of the PNEC. Derivation of PNEC values in the EU risk assessment procedure uses either the application of an assessment factor of $10-1000$ on the least NOEC or the $\mathrm{HC}_{5}$ (based in the SSD approach) divided by a safety factor. ${ }^{44}$ Assessment factors are recognized as a conservative approach for dealing with uncertainty in assessing risks posed by chemicals. ${ }^{23}$ In this assessment, a PNEC of $0.12 \mu \mathrm{g} \mathrm{NP} \mathrm{L}{ }^{-1}$ derived by use of the SSD approach with a $50 \%$ certainty based on reproduction data was recommended as the maximum concentration at which the aquatic organisms is protected when exposure to NP. The PNEC were numerically less than those deriving based on single fish species but in the same order of magnitude. ${ }^{29,30}$ However, this result is lesser by a factor of 50 than the criteria continuous concentration (CCC) of $6.59 \mu \mathrm{g}$ $\mathrm{L}^{-1}$ for protection of aquatic derived by use of ACRs. ${ }^{21}$ Use of ACRs has been criticized, since average ACRs can be inadequate for extrapolation from acute to chronic values. ${ }^{27,28}$ In addition, USEPA developed the CCC for NP mostly based on survival and growth, since no information was available for effects on reproduction. Sensitivity of taxa was greater when reproduction was used as the measurement endpoint. Therefore, the PNEC derived based on reproductive toxicity in present study can better protect aquatic life from exposure to NP. Similarly, Caldwell et al. collected NOECs for reproductive effects from 39 papers in 26 species, resulting in a $\mathrm{HC}_{5}$ of 0.35 $\mathrm{ng} \mathrm{L} \mathrm{L}^{-1}$ for EE2. Reproduction of fish was identified as the most sensitive endpoint in aquatic species. The result is 100 or more times less than concentrations $\left(0.13 \mu \mathrm{g} \mathrm{L}^{-1}\right)$ derived from traditional test endpoints with application of assessment factors. $^{31}$
3.2. Probabilistic Ecological Risk Assessment of NP. The site information and concentrations of NP in surface waters from China is shown in Table 1 . NP was detected in all 16 samples, with concentrations in the range of 30.05-288.75 $\mathrm{ng} \mathrm{L} \mathrm{L}^{-1}$. For the different watersheds and drainage regions, NP was more frequently detected at greater concentrations in the Yangtze River watershed. Compared to results of previous studies in both source and surface waters, these are similar to those determined in the present study. Concentrations of NP in source waters were as great as $130,134,338$, and $890 \mathrm{ng} \mathrm{L}^{-1}$ in the USA, Germany, Greece, and Austria, respectively. ${ }^{46-49}$ NPs and NPEOs have been classified in the European Union as a hazard to safety to humans and the environment. ${ }^{50}$ In the USA, these compounds have been removed from laundry detergents. Nevertheless, these compounds have not been effectively restricted in China. So, concentrations of NP found in various Chinese rivers were often greater than those from other regions. ${ }^{7,51}$

The ecological risk assessment of NP was achieved by applying a tiered ERA approach consisting of simple deterministic methods to probabilistic methods for risk characterization, concentrations of NP from nationwide surface water monitoring program, and toxicity data for different endpoints from previous published literature.

The HQs of NP in Chinese surface waters are shown (Figure 2 ). Risk was assessed and comparing PNECs based on various

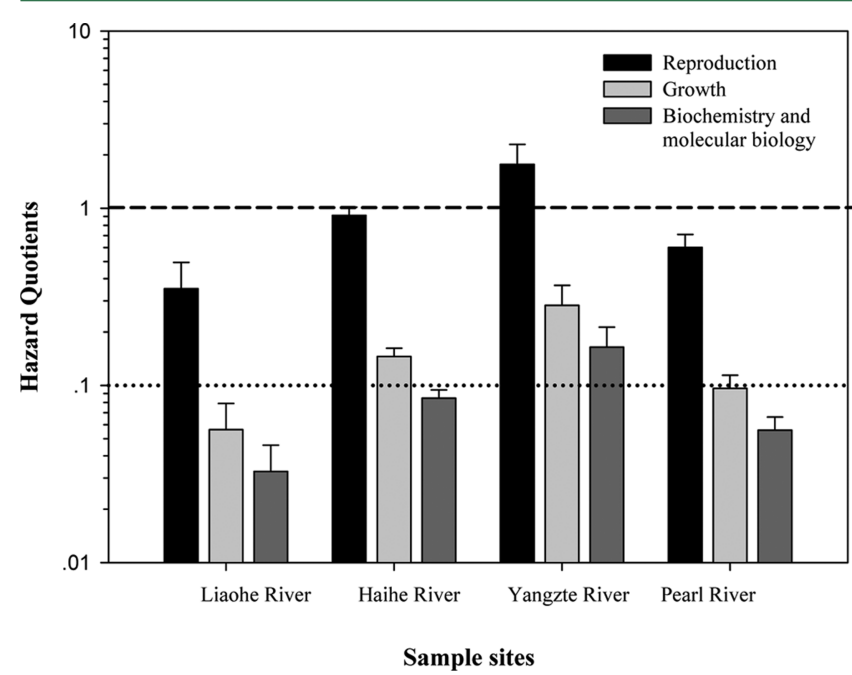

Figure 2. HQs calculated by dividing averages concentrations by PNEC based on different tested endpoints of nonylphenol.

endpoints to mean concentrations in each surface water. For assessments using PNEC derived from reproduction data, the HQs were more than 0.3 in all sample areas and even exceeded 1.0 in the Yangtze River watershed. Based on the PNEC derived from other toxicity data, the HQs were generally less than 0.1 except for the Yangtze River watershed. The results indicated NP posed a potential risk of reproductive system damage to aquatic organisms in Chinese surface water, especially in the Yangtze River.

Joint probability curves (JPCs) resulting from direct comparison of exceedance probability function (EXF, calculated as 100 - cumulative distribution function (CDF)) and SSD offer a better representation of the overall risk (Figure 3 ). The $x$-axis of the JPC represents the intensity of effects, while the $y$-axis represents their probability. Each point on the curve 


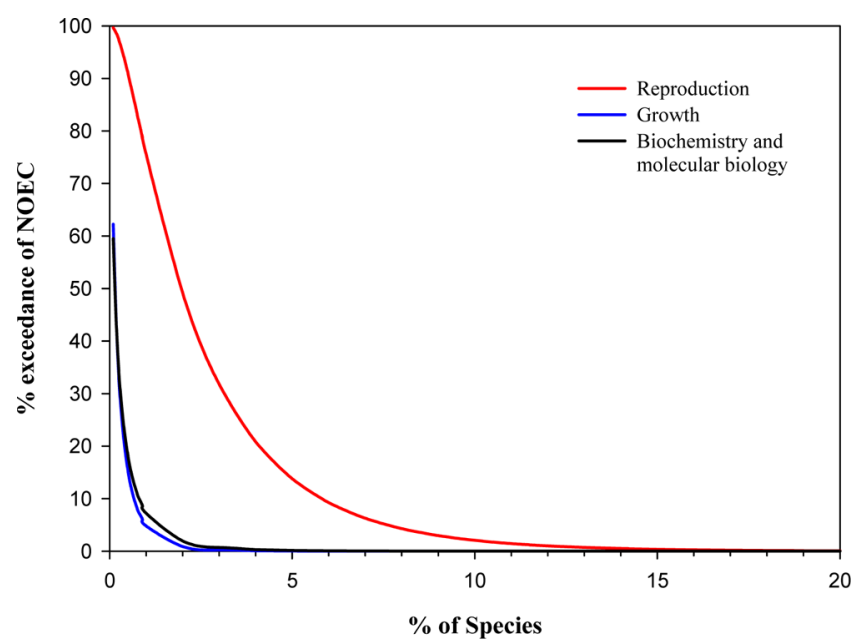

Figure 3. Joint probability curves for ecological risk of nonylphenol in surface water from China.

represents both the probability that the chosen proportion of species will be affected and the frequency with which that magnitude of effect would be exceeded. The closer the JPC is to the axes, the less the probability of adverse effects. ${ }^{45}$ In the present study, probabilities of exceeding the reproductive toxicity NOEC for 1 to $5 \%$ of the species ranged from 14.2 to $76.5 \%$ for NP. The results of the JPC analysis indicate that NP posed a significant risk on aquatic organisms' reproductive systems.

From the results of this study, NP posed a significantly greater risk to reproduction of aquatic organisms than did other measurement endpoints, such as growth and survival. For the different watersheds and drainage regions, NP posed a potential risk of reproductive system damage to aquatic organisms in Chinese surface water, especially in the Yangtze River. Methods ranging from deterministic to probabilistic methods are usually recommended for ecological risk assessment, with the probabilistic approach serving to refine the risk estimated after more conservative lower tier approaches. Results of probabilistic ERAs can provide useful information for risk managers and decision makers. However, hazard quotients, especially the single-value estimates, still have the advantage of readily identifying chemicals that have a likelihood of producing effects on species. The single-value estimate method is useful as a screening tool that can help to focus risk assessments. The initial estimations found in the first tier of the present study, which predicted relatively large HQs, suggested that a generalized potential risk for the whole area could not be excluded. The higher tier approaches allowed the estimation of the proportional risk of measured NP concentrations to aquatic species in Chinese surface waters.

3.3. Uncertainty Analysis. Uncertainty in ERA is inevitable even when higher-tier methods are used. Sources of uncertainty in the present study include the following: the variability of nonylphenol concentration within a single body of water, the ecological relevance of the toxicity data, and the risk characterization model. In particular, information on spatial and temporal variation in concentrations of NP was limited, especially for a nationwide monitoring. To more accurately describe exposures, further information needs to be collected to describe concentrations of NP at various spatial and temporal scales.
In the present study, toxicity values based on different tested endpoints for aquatic species from different trophic concentrations were used to decrease uncertainty associated with species-specific responses and to better mimic real-world scenarios of long-term exposure. It is commonly thought that different ecosystems contain different biological constituents, and a concentration threshold that would be harmless in one ecosystem may lead to irreversible toxic effects on others. The potential use of toxicity data for non-native species to derive WQC is controversial, due to the fact that it is sometimes questioned whether criteria based on species from one geographical region provide appropriate protection for species in a different region. ${ }^{52,53}$ However, this uncertainty could not be resolved previously in large part due to the paucity of toxicity data applicable for local species. Comparisons of sensitivities between native and non-native species for limited chemicals, such as 2,4-dichlorophenol and pentachlorophenol, ${ }^{17,54}$ revealed that values derived by use of non-native species values were protective of native species when a safety factor was included. It indicates that data for organisms from different geographic regions can be used in estimating PNEC for a preliminary ecological risk assessment when lacking of site-specific toxicity data. When conducting ERAs for chemicals that can modulate the neuroendocrine system, information on chronic effects including subtle effects on reproduction should be used to derive thresholds to which to compare predicted environmental concentrations. However, there is limited information of this type available, especially for local species, especially for site-specific ERAs. So, reproductive toxicities data for endocrine disrupters for site-specific species are critically needed in order to produce more accurate ecological risk assessments.

$\mathrm{NP}$ is a degradation product of nonylphenol ethoxylates (NPE), which is used in detergents found in cleaning products, pesticides, and personal care products. This breakdown process produces a number of chemicals with structures intermediate between NPE and NP. Because these related chemicals come from the same parent compound as NP (i.e., the original NPE detergent), they will always be present in the mixture and always accompany NP in aquatic environments. Mixtures may be much more toxic than NP alone. Because insufficient data exist to reliably analyze mixtures, then a safety factor (five in present study) was introduced to take into account related chemicals. Also, the lack of consensus on ERA methods precluded effective comparison among calculated risks made by different risk assessors. Standard methods should be developed and employed by researchers and public agencies to evaluate ecological risk.

The results of the study upon which we report here demonstrate the use of the probabilistic ERA approach based on comparing PNECs derived based on reproductive fitness to concentrations of NP in Chinese surface water. In this study, PNECs for NP were derived based either on endpoints of survival, development and growth or on some nonlethal biomarkers of reproduction, biochemical and molecular biology data. Reproduction data was more sensitive than other test endpoints for exposure of NP to aquatic organisms based on comparison both PNEC and sensitivity distribution. For NP, applications of more traditional assessment endpoints were less protective than application of PNECs based on nontraditional EDC endpoints. In addition, NP was found to have potential ecological risk in some Chinese surface waters. Risks were greatest in the Yangtze River Basin, which were significantly 
greater than those for other basins. The use of NP might affect the aquatic organisms, and corresponding measures should be taken to minimize ecological risk posed by NP, especially in the Yangtze River Basin.

\section{ASSOCIATED CONTENT}

\section{S Supporting Information}

Toxicity data for NP were collected from existing toxicity databases (e.g., ECOTOX Database, http://cfpub.epa.gov/ ecotox/), published in the literature, and government document follow the principles of accuracy, relevance, and reliability. This material is available free of charge via the Internet at http://pubs.acs.org.

\section{AUTHOR INFORMATION}

\section{Corresponding Author}

*Phone: +86-10-6284-9140. Fax: +86-10-6292-3543. E-mail: wangzj@rcees.ac.cn.

Notes

The authors declare no competing financial interest.

\section{ACKNOWLEDGMENTS}

This research was financially supported by National Natural Science Foundation of China (21307165) and National Major S\&T Program for Water Pollution Control and Treatment (2013ZX07502001). Prof. Giesy was supported by the Canada Research Chair program, a Visiting Distinguished Professorship in the Department of Biology and Chemistry and State Key Laboratory in Marine Pollution, City University of Hong Kong, the 2012 "High Level Foreign Experts" (\#GDW20123200120) program, funded by the State Administration of Foreign Experts Affairs, the P.R. China to Nanjing University and the Einstein Professor Program of the Chinese Academy of Sciences. We also would like to thank Dr. Weiwei Jiang (National Engineering Research Center of Urban Water Resources, China) for the assistance with chemical analysis.

\section{REFERENCES}

(1) Ying, G.-G.; Williams, B.; Kookana, R. Environmental fate of alkylphenols and alkylphenol ethoxylates-a review. Environ. Int. 2002, 28 (3), 215-226.

(2) Fawell, J.; Sheahan, D.; James, H.; Hurst, M.; Scott, S. Oestrogens and oestrogenic activity in raw and treated water in severn trent water. Water Res. 2001, 35 (5), 1240-1244.

(3) Kannan, K.; Keith, T.; Naylor, C.; Staples, C.; Snyder, S.; Giesy, J. Nonylphenol and nonylphenol ethoxylates in fish, sediment, and water from the Kalamazoo River, Michigan. Arch. Environ. Contam. Toxicol. 2003, 44 (1), 77-82.

(4) Tsuda, T.; Takino, A.; Muraki, K.; Harada, H.; Kojima, M. Evaluation of 4-nonylphenols and 4-tert-octylphenol contamination of fish in rivers by laboratory accumulation and excretion experiments. Water Res. 2001, 35 (7), 1786-1792.

(5) Soares, A.; Guieysse, B.; Jefferson, B.; Cartmell, E.; Lester, J. Nonylphenol in the environment: a critical review on occurrence, fate, toxicity and treatment in wastewaters. Environ. Int. 2008, 34 (7), $1033-1049$.

(6) Xu, J.; Wang, P.; Guo, W.; Dong, J.; Wang, L.; Dai, S. Seasonal and spatial distribution of nonylphenol in Lanzhou Reach of Yellow River in China. Chemosphere 2006, 65 (9), 1445-1451.

(7) Shao, B.; Hu, J.; Yang, M.; An, W.; Tao, S. Nonylphenol and nonylphenol ethoxylates in river water, drinking water, and fish tissues in the area of Chongqing, China. Arch. Environ. Contam. Toxicol. 2005, 48 (4), 467-473.

(8) Jiang, W.; Yan, Y.; Ma, M.; Wang, D.; Luo, Q.; Wang, Z.; Satyanarayanan, S. K. Assessment of source water contamination by estrogenic disrupting compounds in China. J. Environ. Sci. 2012, 24 (2), 320-328.

(9) Bandiera, S. M. Reproductive and endocrine effects of pnonylphenol and methoxychlor: a review. Immunol., Endocr. Metab. Agents Med. Chem. 2006, 6 (1), 15-26.

(10) Nimrod, A. C.; Benson, W. H. Environmental estrogenic effects of alkylphenol ethoxylates. CRC Crit. Rev. Toxicol. 1996, 26 (3), 335364.

(11) Giesy, J. P.; Pierens, S. L.; Snyder, E. M.; Miles-Richardson, S.; Kramer, V. J.; Snyder, S. A.; Nichols, K. M.; Villeneuve, D. A. Effects of 4-nonylphenol on fecundity and biomarkers of estrogenicity in fathead minnows (Pimephales promelas). Environ. Toxicol. Chem. 2000, 19 (5), 1368-1377.

(12) Zha, J. M.; Sun, L. W.; Spear, P. A.; Wang, Z. J. Comparison of ethinylestradiol and nonylphenol effects on reproduction of Chinese rare minnows (Gobiocypris rarus). Ecotoxicol. Environ. Saf. 2008, 71 (2), 390-399.

(13) Hill, R. L.; Janz, D. M. Developmental estrogenic exposure in zebrafish (Danio rerio): I. Effects on sex ratio and breeding success. Aquat. Toxicol. 2003, 63 (4), 417-429.

(14) Jobling, S.; Sumpter, J. P.; Sheahan, D.; Osborne, J. A.; Matthiessen, P. Inhibition of testicular growth in rainbow trout (Oncorhynchus mykiss) exposed to estrogenic alkylphenolic chemicals. Environ. Toxicol. Chem. 1996, 15 (2), 194-202.

(15) Tanaka, J. N.; Grizzle, J. M. Effects of nonylphenol on the gonadal differentiation of the hermaphroditic fish, Rivulus marmoratus. Aquat. Toxicol. 2002, 57 (3), 117-125.

(16) Weber, L. P.; Hill, R. L.; Janz, D. M. Developmental estrogenic exposure in zebrafish (Danio rerio): II. Histological evaluation of gametogenesis and organ toxicity. Aquat. Toxicol. 2003, 63 (4), 431446.

(17) Jin, X. W.; Zha, J. M.; Xu, Y. P.; Wang, Z. J.; Kumaran, S. S. Derivation of aquatic predicted no-effect concentration (PNEC) for 2,4-dichlorophenol: Comparing native species data with non-native species data. Chemosphere 2011, 84 (10), 1506-1511.

(18) Bakke, D. Human and ecological risk assessment of nonylphenol polyethoxylate-based (NPE) surfactants in Forest Service herbicide applications. Unpublished report by the Forest Service Pacific Southwest Regional Pesticide Use Specialist 2003. http://www.fs. usda.gov/Internet/FSE_DOCUMENTS/stelprdb5346866.pdf (accessed December 18, 2013).

(19) Environment Canada, Priority Substances List Assessment Report: Nonylphenol and its ethoxylates, 2000; ISBN 0-662-29248-0. http://www.ec.gc.ca/substances/ese/eng/psap/final/npe.cfm (accessed December 18, 2013).

(20) USEPA RM-1 Document and Meeting Summary for Nonylphenol. Prepared by D. Rodier, CSRAD, US Environmental Protection Agency: 1996.

(21) USEPA, National Recommended Water Quality Criteria, United States Environmental Protection Agency: Washington, DC, USA, 2006.

(22) Ackermann, G. E.; Schwaiger, J.; Negele, R. D.; Fent, K. Effects of long-term nonylphenol exposure on gonadal development and biomarkers of estrogenicity in juvenile rainbow trout (Oncorhynchus mykiss). Aquat. Toxicol. 2002, 60 (3), 203-221.

(23) Chapman, P. M.; Fairbrother, A.; Brown, D. A critical evaluation of safety (uncertainty) factors for ecological risk assessment. Environ. Toxicol. Chem. 1998, 17 (1), 99-108.

(24) Crane, M.; Newman, M. C. What level of effect is a no observed effect? Environ. Toxicol. Chem. 2000, 19 (2), 516-519.

(25) Isnard, P.; Flammarion, P.; Roman, G.; Babut, M.; Bastien, P.; Bintein, S.; Essermeant, L.; Ferard, J. F.; Gallotti-Schmitt, S.; Saouter, E.; Saroli, M.; Thiebaud, H.; Tomassone, R.; Vindimian, E. Statistical analysis of regulatory ecotoxicity tests. Chemosphere 2001, 45 (4-5), $659-669$.

(26) Roex, E. W. M.; Van Gestel, C. A.; Van Wezel, A. P.; Van Straalen, N. M. Ratios between acute aquatic toxicity and effects on population growth rates in relation to toxicant mode of action. Environ. Toxicol. Chem. 2000, 19 (3), 685-693. 
(27) Besser, J. M.; Wang, N.; Dwyer, F. J.; Mayer, F. L.; Ingersoll, C. G. Assessing contaminant sensitivity of endangered and threatened aquatic species: Part II. Chronic toxicity of copper and pentachlorophenol to two endangered species and two surrogate species. Arch. Environ. Contam. Toxicol. 2005, 48 (2), 155-165.

(28) Brix, K. V.; DeForest, D. K.; Adams, W. J. Assessing acute and chronic copper risks to freshwater aquatic life using species sensitivity distributions for different taxonomic groups. Environ. Toxicol. Chem. 2001, 20 (8), 1846-1856.

(29) EC European Union Risk-Assessment Report Vol. 10, 2002 on 4-nonylphenol (branched) and nonylphenol, European Chemicals Bureau, Joint Research Centre, European Commission: Ispra, Italy, 2001; ISBN 92-827-801. http://ecb.jrc.it/existing-chemicals (accessed December 18, 2013).

(30) Lin, B.; Tokai, A.; Nakanishi, J. Approaches for establishing predicted-no-effect concentrations for population-level ecological risk assessment in the context of chemical substances management. Environ. Sci. Technol. 2005, 39 (13), 4833-4840.

(31) Caldwell, D. J.; Mastrocco, F.; Hutchinson, T. H.; Lange, R.; Heijerick, D.; Janssen, C.; Anderson, P. D.; Sumpter, J. P. Derivation of an aquatic predicted no-effect concentration for the synthetic hormone, 17 alpha-ethinyl estradiol. Environ. Sci. Technol. 2008, 42 (19), 7046-7054.

(32) Hutchinson, T. H.; Ankley, G. T.; Segner, H.; Tyler, C. R. Screening and testing for endocrine disruption in fish - Biomarkers as "signposts," not "traffic lights," in risk assessment. Environ. Health Perspect. 2006, 114, 106-114.

(33) Solomon, K. R.; Baker, D. B.; Richards, R. P.; Dixon, D. R.; Klaine, S. J.; LaPoint, T. W.; Kendall, R. J.; Weisskopf, C. P.; Giddings, J. M.; Giesy, J. P.; Hall, L. W.; Williams, W. M. Ecological risk assessment of atrazine in North American surface waters. Environ. Toxicol. Chem. 1996, 15 (1), 31-74.

(34) Solomon, K. R.; Takacs, P. Probabilistic risk assessment using species sensitivity distributions. Posthuma, L, Suter, G. W., II, Traas, T. P., Eds.; Species Sensitivity Distributions in Ecotoxicology; Lewis: Boca Raton, FL, USA, 2002; pp 285-314.

(35) Brain, R. A.; Sanderson, H.; Sibley, P. K.; Solomon, K. R. Probabilistic ecological hazard assessment: Evaluating pharmaceutical effects on aquatic higher plants as an example. Ecotoxicol. Environ. Saf. 2006, 64 (2), 128-135.

(36) Giesy, J. P.; Solomon, K. R.; Coats, J. R.; Dixon, K. R; Giddings, J. M.; Kenaga, E. E. Chlorpyrifos: Ecological risk assessment in North American aquatic environments. Rev. Environ. Contam. Toxicol. 1999, $160,1-129$.

(37) Hunt, J.; Birch, G.; Warne, M. S. J. Site-specific probabilistic ecological risk assessment of a volatile chlorinated hydrocarboncontaminated tidal estuary. Environ. Toxicol. Chem. 2010, 29 (5), $1172-1181$.

(38) Zolezzi, M.; Cattaneo, C.; Tarazona, J. V. Probabilistic ecological risk assessment of 1,2,4-trichlorobenzene at a former industrial contaminated site. Environ. Sci. Technol. 2005, 39 (9), 29202926.

(39) Jin, X.; Gao, J.; Zha, J.; Xu, Y.; Wang, Z.; Giesy, J. P.; Richardson, K. L. A tiered ecological risk assessment of three chlorophenols in Chinese surface waters. Environ. Sci. Pollut. Res. 2012, 19 (5), 1544-1554.

(40) Klimisch, H. J.; Andreae, M.; Tillmann, U. A systematic approach for evaluating the quality of experimental toxicological and ecotoxicological data. Regul. Toxicol. Pharmacol. 1997, 25 (1), 1-5.

(41) Aldenberg, T.; Slob, W. Confidence-limits for hazardous concentrations based on logistically distributed NOEC toxicity data. Ecotoxicol. Environ. Saf. 1993, 25 (1), 48-63.

(42) Jin, X.; Zha, J.; Xu, Y.; Wang, Z.; Giesy, J.; Richardson, K. Derivation of predicted no effect concentrations (PNEC) for 2,4,6trichlorophenol based on Chinese resident species. Chemosphere 2012, $86,17-23$.

(43) Wheeler, J. R.; Grist, E. P. M.; Leung, K. M. Y.; Morritt, D.; Crane, M. Species sensitivity distributions: data and model choice. Mar. Pollut. Bull. 2002, 45 (1-12), 192-202.
(44) ECB, Technical guidance document on risk assessment in support of commission directive 93/67/EEC on risk assessment for new notified substances, commission regulation (EC) no. 1488/94 on risk assessment for existing sunstances, derective $98 / 8 / \mathrm{EC}$ of the European Parliament and of the Council concerning the placing of biocidal products on the market. Part II. Environmental Risk Assessment. European Chemicals Bureau, European Commission Joint Research Center, European Communities. In 2003.

(45) Solomon, K.; Giesy, J.; Jones, P. Probabilistic risk assessment of agrochemicals in the environment. Crop Prot. 2000, 19 (8-10), 649655.

(46) Benotti, M. J.; Trenholm, R. A.; Vanderford, B. J.; Holady, J. C.; Stanford, B. D.; Snyder, S. A. Pharmaceuticals and endocrine disrupting compounds in US drinking water. Environ. Sci. Technol. 2008, 43 (3), 597-603.

(47) Arditsoglou, A.; Voutsa, D. Partitioning of endocrine disrupting compounds in inland waters and wastewaters discharged into the coastal area of Thessaloniki, Northern Greece. Environ. Sci. Pollut. Res. 2010, 17 (3), 529-538.

(48) Kuch, H. M.; Ballschmiter, K. Determination of endocrinedisrupting phenolic compounds and estrogens in surface and drinking water by HRGC-(NCI)-MS in the picogram per liter range. Environ. Sci. Technol. 2001, 35 (15), 3201-3206.

(49) Hohenblum, P.; Gans, O.; Moche, W.; Scharf, S.; Lorbeer, G. Monitoring of selected estrogenic hormones and industrial chemicals in groundwaters and surface waters in Austria. Sci. Total Environ. 2004, 333 (1), 185-193.

(50) Commission, E. Directive 2003/53/EC of the European Parliament and of the Council of 18 June 2003 amending for the 26th time Council Directive 76/769/EEC relating to restrictions on the marketing and use of certain dangerous substances and preparations (nonylphenol, nonylphenol ethoxylate and cement). Off. J. Eur. Union 2003, 178, 24-178.

(51) Yu, Y.; Zhai, H.; Hou, S.; Sun, H. Nonylphenol ethoxylates and their metabolites in sewage treatment plants and rivers of Tianjin, China. Chemosphere 2009, 77 (1), 1-7.

(52) Kwok, K. W. H.; Leung, K. M. Y.; Lui, G. S. G.; Chu, V. K. H.; Lam, P. K. S.; Morritt, D.; Maltby, L.; Brock, T.; Van den Brink, P. J.; Warne, M. S. J. Comparison of tropical and temperate freshwater animal species' acute sensitivities to chemicals: Implications for deriving safe extrapolation factors. Integr. Environ. Assess. Manage. 2007, 3 (1), 49-67.

(53) Maltby, L.; Blake, N.; Brock, T. C. M.; Van Den Brink, P. J. Insecticide species sensitivity distributions: Importance of test species selection and relevance to aquatic ecosystems. Environ. Toxicol. Chem. 2005, 24 (2), 379-388.

(54) Jin, X.; Zha, J.; Xu, Y.; John, P. G; Wang, Z. Toxicities of pentachlorophenol to native aquatic species in the Yangtze River. Environ. Sci. Pollut. Res. 2012, 19 (3), 609-618. 